\title{
Mudanças Climáticas: Um desafio intercultural e inter-religioso
}

\author{
Pe. Josafá Carlos de Siqueira SJ
}

O planeta Terra já viveu, ao longo da história geológica, muitos momentos de impactos causados pelas mudanças do clima, ora com o esfriamento dos períodos glaciais, ora com o aquecimento e aumento dos regimes pluviométricos responsáveis pelo surgimento da tropicalidade entre os trópicos de câncer e capricórnio. Graças a esta tropicalidade, associada a outros processos evolutivos e ecológicos, é que apareceram os diversos pontos de megabiodiversidade na terra, considerados hoje como uma riqueza territorial dos países detentores.

Considerando essa realidade geológica passada, não podemos ignorar que, na história mais recente, a humanidade também passou por momentos de mudanças climáticas de resfriamento e aquecimento, com sérias conseqüências sociais e ambientais, tanto no hemisfério norte como no sul.

Hoje, as ciências modernas nos têm mostrado indicadores que comprovam o fato de que estamos vivendo um novo processo de mudanças climáticas, percebidos nos danos ambientais causados pelos desequilíbrios entre a racionalidade produtivista e desenvolvimentista e a incapacidade do planeta em assimilar e integrar as sucatas e lixos dos modelos insustentáveis. No passado, as forças dos fenômenos oriundos da natureza amedrontavam as pessoas e as sociedades, que atribuíam a tais fatos uma vingança dos deuses ou de Deus, por razões morais de comportamentos não adequados do ser humano aos desígnios do Criador.

Hoje, dentro de uma cultura marcada pelo progresso científico, conhecemos as causas dos fenômenos da natureza e possuímos instrumentais 
técnicos suficientes para fazer previsões, embora, em alguns casos, ainda não controlamos fenômenos da natureza que causam danos em grande escala no nível local e mundial. Por outro lado, somos também cada vez mais conscientes que algumas catástrofes são conseqüências das alterações que fomos provocando no frágil equilíbrio do planeta.

A consciência humana planetária assume o fato de que as mudanças climáticas estão profundamente relacionadas com a problemática dos modelos e das opções sociais e políticas feitas pela sociedade moderna e contemporânea. Se de um lado existe uma dimensão de culpabilidade antropológica, de outro, o ser humano se vê diante de uma dupla responsabilidade, a saber: minimizar e buscar cientificamente soluções para administrar os passivos acumulados na atmosfera e de outros problemas relacionados com a destruição da natureza, como também o desafio das mudanças éticas de posturas e hábitos para que o planeta mantenha um mínimo de condições de sustentabilidade para as gerações presentes e futuras.

Os acontecimentos relacionados com as mudanças climáticas são cada vez mais percebidos pelos desequilíbrios na dinâmica da natureza, cujas conseqüências repercutem, diretamente, na sociedade, onde milhares de pessoas são afetadas, com perdas materiais e mortes. A dramaticidade desses contínuos e sucessivos fenômenos põe fim de uma era onde se imaginava que a esfera do horizonte global estava relacionada, simplesmente, com um pensar teórico, relegando para o nível local um agir desarticulado e voluntarista.

Esse modo de pensar vem sendo, progressivamente, superado, pois, a ligação entre os problemas das mudanças climáticas locais e globais estão intimamente, relacionados. Uma ação local contribui positivamente ou negativamente para os problemas globais e vice-versa (SIQUEIRA, 2009, p.40). Esta interrelação ajuda a superar a abstração teórica de um pensar, puramente, solidário e nos reporta à concretude de um agir inter-solidário, onde as pequenas ações passam a ser valorizadas e, profundamente, necessárias para a superação dos desequilíbrios na relação do ser humano com a natureza. Um simples plantio de uma árvore seqüestradora de carbono é uma ação local que contribui com a problemática do aquecimento global. Aos poucos vamos tomando consciência de que a pequenez de ações potenciais e sustentáveis é uma saída necessária e imprescindível para a superação de problemas que atingem toda a humanidade, independente do lugar geográfico, raças, línguas e culturas. Nesse sentido é que podemos entender a relação entre mudanças climáticas e o fenômeno da interculturalidade.

A cultura moderna se caracteriza pelas múltiplas manifestações de valores, onde as diferentes identidades procuram não só afirmar os seus princípios, crenças e convicções, mas também a busca de um diálogo inter- 
cultural e inter-religioso; pois, somente, assim é que se torna possível discutir os problemas das mudanças climáticas e buscar soluções locais e regionais para uma questão de interesse global. A universalidade das informações permite conhecer as riquezas, os valores e as contradições dos diferentes povos e culturas, abrindo-se para uma dimensão planetariamente solidária.

Nessa perspectiva, as informações eletronicamente, disponíveis sobre as mudanças climáticas, suas conseqüências e as soluções minimizadoras, são conhecidas e compartilhadas entre povos e nações, independente das distâncias geográficas. As repercussões das mudanças climáticas, seja por via eletrônica ou televisiva, acontecem num momento privilegiado da nossa história, pois existe um clamor por uma cosmovisão mais integradora do mundo, certamente, condicionado pelo processo de ascensão progressiva da consciência ecológica planetária.

A tomada de consciência de que uma ação local afeta ou contribui, positivamente, para minimizar uma problemática mais global, faz com que as questões das mudanças climáticas sejam tratadas, solidariamente, entre diferentes culturas. A temática tem permitido a união de esforços científicos e éticos, pois não basta conhecer e fazer previsões dos fenômenos relacionados com as mudanças climáticas, e nem tão pouco a criação de ações mitigadoras e transferências de tecnologias, mas é preciso também uma visão compartilhada e responsável que tenha como meta uma mudança dos hábitos insustentáveis para permitir o processo de construção de costumes (ethos) social e ambientalmente sustentáveis.

Como o assunto está, profundamente, relacionado com a qualidade de vida social e ambiental, não podemos esquecer os paradoxos que permeiam as relações interculturais. Se por um lado cresce a consciência mundial e o desejo de encontrar soluções mais imediatas para as questões relacionadas com as mudanças climáticas, por outro, a humanidade tem dificuldades em frear ou repensar os padrões consumistas que condicionam o modo de ser e de agir das pessoas. Esta relação entre a consciência dos limites do planeta e a dificuldade de mudança de padrão e ritmo de vida, constitui uma aporia permanente na comunidade mundial (SIQUEIRA, 2009, p.25).

A dificuldade está em saber até quando vamos conseguir conviver com esta aporia, pois os sinais das mudanças climáticas já estão sendo visibilizados, localmente, e globalmente. O que, realmente, nos preocupa são as escalas das mudanças climáticas, pois se no passado as mesmas eram longevas e lentas, no presente estão se tornando cada vez mais curtas e aceleradas. Como as mudanças de hábitos e costumes na sociedade são lentas, o perigo consiste no descompasso entre o ritmo da natureza e o ritmo da socie- 
dade. Daí a importância das mudanças éticas das posturas e ações que possam minimizar e desacelerar as causas que provocam as mudanças climáticas.

Para que ocorram essas mudanças éticas, e todo o processo de adaptação da sociedade a essa nova realidade, condicionada pelas mudanças climáticas, é necessário, além do papel do Estado, no estabelecimento de políticas públicas e das Universidades na construção dos saberes científicos, a colaboração solidária do potencial ético e moral das religiões.

A ética das religiões, desde os tempos mais remotos, sempre foi algo importante para a formação dos hábitos e costumes dos diferentes povos que habitam o planeta. Além da preocupação com a formação moral da pessoa humana, as diversas religiões, espalhadas por todos os recantos da terra, também contribuem para a formação de valores sociais e culturais. Desta forma, quando se fala da problemática das mudanças climáticas, não resta dúvida de que as religiões tradicionais e recentes podem exercer um papel importante, tanto nas mudanças de hábitos e costumes, como na formação de uma consciência crítica dos modelos, cujas ações e práticas são insustentáveis. Elas também desempenham um papel importante em ajudar no processo de aproximação do ser humano com Deus e com a natureza, contribuindo para desmaterializara perspectiva, puramente, horizontal da vida e resgatar a Aliança entre todos os seres viventes, conforme o relato do Livro do Gênesis 9,9-17.

Sem entrar em pormenores das especificidades existentes em cada manifestação religiosa e nem das diferentes cosmovisões que plasmam o modo de ser e agir de cada religião, não podemos ignorar que todas elas podem contribuir, de diferentes maneiras, para o enfrentamento dos desafios atuais das mudanças climáticas, sobretudo no que diz respeito aos aspectos ético-religiosos e ético-educativos.

No que diz respeito aos aspectos ético-religiosos, é fundamental o resgate da visão cosmocêntrica, onde as questões teológicas, antropológicas e cosmológicas, estão, profundamente, unidas e imbricadas. Em todas as religiões essas três dimensões estão presentes, porém, muitas vezes são tratadas, desarticuladamente, ou pensadas de maneira fragmentada ou conflitiva. Mesmo conservando as suas respectivas tradições espirituais e teológicas específicas, é preciso, num mundo globalizado, resgatar esta tríplice união, pois, somente, ela é que possibilitará a dar uma resposta ética mais efetiva de uma problemática que está relacionada com todos os que habitam o mesmo planeta. O papel de saber re-ligar, que é missão de todas as religiões, é importante para o resgate da visão cosmocêntrica, rompendo com as cosmovisões dualistas e fragmentadas, onde o divino, o humano e o cósmico são tratados separadamente. 
Outro aspecto importante na perspectiva ético-religiosa consiste na abordagem da Aliança, tema tão caro às diferentes teologias. Embora a temática seja por vez abordada de maneira diferente, quase todas as religiões possuem um enfoque voltado para a Aliança entre Criador e criaturas. A dimensão positiva da Aliança é fundamental, tanto para unir o ser humano com o divino e a natureza, como também para revelar a epifania do Criador. A ênfase na temática da Aliança suscita valores éticos do saber respeitar e cuidar, a responsabilidade compartilhada, a administração responsável e a destinação universal daquilo que é dado, gratuitamente, por Deus ao ser humano.

Nos aspectos ético-educativos, todas as religiões possuem um enorme potencial de reeducação do ser humano, ajudando a corrigir os hábitos individualistas, egoístas e destrutivos com as outras pessoas e com o meio ambiente, e proporcionando uma formação mais comunitária, fraterna e solidária com todos que habitam a mesma casa planetária. Os eventos cultuais, as celebrações, as exortações mistagógicas, as catequeses, os retiros e tantas outras formas de encontro religioso, poderiam ser momentos importantes onde se pode associar a sabedoria das escrituras sagradas com a temática do meio ambiente. O importante é que os crentes das diferentes religiões sejam informados, corretamente, sobre a seriedade das mudanças climáticas e as suas conseqüências para o planeta, a sociedade e toda a obra do Criador.

Os dados sérios dos diferentes campos dos saberes científicos, não permitem mais duvidar dos limites planetários a que estamos chegando e a importância de enfrentar a problemática, unindo esforços das ciências com a perspectiva da fé, onde imanência e transcendência estão, profundamente, imbricadas. Evitando hermenêuticas fundamentalistas, anacrônicas e catastróficas, as religiões poderiam oferecer subsídios críticos para que os homens e as mulheres de fé possam meditar, orar, rezar e discernir sobre a missão de preservar a obra do Criador, o destino sobrenatural das criaturas e a importância do engajamento concreto em ações que possam minimizar os efeitos das mudanças climáticas. A relação entre fé e obras, tema de relevância para as religiões, envolveria não apenas as relações antropológicas, mas também todas as ações que tivessem como objetivo a busca de soluções locais e globais em favor da sustentabilidade do planeta e a preservação do patrimônio criacional. Como as religiões são, pedagogicamente, importantes na formação do ethos cultural e religioso, nada mais nobre do que testemunhar, com palavras e ações concretas, as atitudes pessoais e comunitárias, verdadeiramente, voltadas para a sustentabilidade da casa planetária, colocada por Deus em nossas mãos para que possamos administrá-la com sabedoria e responsabilidade. 
Além desses aspectos, é importante também que o próprio território geográfico do templo religioso possa espelhar o exemplo e o compromisso com o meio ambiente, reciclando os seus resíduos, adotando técnicas de reuso, evitando o desperdício, plantando árvores para seqüestrar o carbono, economizando água e energia, usando energias alternativas, evitando a poluição sonora, entre outras. A construção de templos dentro de padrões sustentáveis não deixaria de ser um testemunho vivo e concreto das religiões para a sociedade, ganhando a credibilidade não apenas daqueles que estão ligados a um determinado credo, mas também de pessoas de outras religiões, ecologistas, cientistas, ambientalistas e não crentes.

Para finalizar, cremos que diante das mudanças climáticas e seus impactos na sociedade e no meio ambiente, as religiões poderiam formular, inspirados em suas teologias e espiritualidades, princípios éticos que orientassem as ações concretas de seus seguidores, voltadas para a sustentabilidade planetária. Exponho, a seguir, algumas dessas ações.

1. Ajudar as pessoas na compreensão sobre a importância da relação profunda entre o Criador e todas as criaturas existentes no planeta Terra.

2. Procurar viver o espírito da Aliança entre o Criador e todas as criaturas, espírito esse que supõe compromisso em preservar as diferentes manifestações de Deus na natureza, privilegiando as vidas mais vulneráveis e ameaçadas.

3. Organizar, com crianças e jovens, atividades educativas e culturais que expressem a preocupação da religião com a sustentabilidade do planeta. Vejamos alguns exemplos: Festivais de músicas com enfoque religioso e ecológico. Peças de teatro que mostrassem os sinais negativos e as contradições da relação entre Criador e criaturas, como também as dimensões positivas que precisam ser resgatadas e vividas. Passeios ecológicos que proporcionassem, através de meditação e contemplação, uma maior relação da pessoa com a natureza. Livros e apostilas que pudessem contar e mostrar os limites do planeta e a importância da fé para ajudar a reverter uma situação negativa. Organizar vídeos e filmes que mostrem como os valores de sua religião podem contribuir para melhorar a vida do planeta e ajudar na superação de barreiras e obstáculos.

4. Fazer com que a área geográfica e os templos religiosos possam testemunhar o desejo de sua religião em contribuir para minimizar os impactos 
do aquecimento global, optando pelas energias alternativas, ampliando a área verde, reciclando os resíduos, etc.

5. Manter o diálogo inter-religioso com outras crenças e credos, com o objetivo de irmanar esforços que revelem a contribuição das religiões para preservar a obra do Criador e o seu desejo em salvar a todos, como nos recorda o Salmo 36,7: "Senhor, tu salvas os homens e os animais".

\section{Referências Bibliográficas}

MOSER, A., O problema ecológico e suas implicações éticas. Vozes, Petrópolis, 1992.

RUBIO, A. GARCÍA, Unidade na pluralidade. Paulinas, São Paulo, 1990.

CNBB, Manual da Campanha da Fraternidade de 2011. Ed. CNBB, Brasília, 2010.

FONSECA, D.P.R. \& SIQUEIRA, J.C., Meio ambiente, cultura e Desenvolvimento Sustentável. Historia/Sete Letras, Rio de Janeiro, 2002.

FLEURY, J. M., Aquecimento global: O que podemos fazer! Ed.Kelps, Goiânia, Goiás, 2009.

JOÃO PAULO II, Carta Apostólica "Sollicitudo Rei Socialis. Paulus, SãoPaulo, 1987.

SILVA, J.J.M., Indicações para uma espiritualidade do cuidado à luz da teologia da criação. Atualidade Teológica 36 (2010) pp.410-418.

SIQUEIRA, J.C., Ética e meio ambiente. Loyola, São Paulo, 2002.

2008.

, Espiritualidade e meio ambiente, PUC-Rio, Rio de Janeiro,

, Impactos das mudanças climáticas na biodiversidade. Pesquisas Botânica 61(2010) pp.325-329.

, Ética Socioambiental. PUC-Rio, Rio de Janeiro, 2009.

\section{Resumo}

O presente artigo consiste numa reflexão sobre a importância do diálogo intercultural e inter-religioso diante do fenômeno local e global das mudanças climáticas. $\mathrm{O}$ autor procura mostrar o papel importante das religiões, tanto na formação ética como no testemunho de padrões, socialmente, justos e, ecologicamente, sustentáveis.

Palavras-chave: Mudanças Climáticas, Diálogo, Intercultural, Interreligioso. 


\begin{abstract}
The paper is a reflection on the importance of both inter-cultural and interreligious dialogues in view of local and global climatic changes. The author shows the important role of religions both for the formation in ethics as well as for the testimony behavior of social justice and ecology sustainable patterns.
\end{abstract}

Keywords: Changes in Climatic, Dialog, Inter-cultural, Inter-religious.

Pe. Josafá Carlos de Siqueira SJ

Reitor da Pontifícia Universidade Católica do Rio de Janeiro Professor do Depto. de Geografia e Meio Ambiente da PUC-Rio

Doutor em Biologia Vegetal

E-mail: josafa@puc-rio.br

Comunicação Recebida em 17/03/11

Comunicação Aprovada em 30/03/11 